\title{
Théophile Gautier, L'Hirondelle et le corbeau, écrits sur Gérard de Nerval
}

\section{Lise Sabourin}

\section{(2) OpenEdition}

1 Journals

\section{Édition électronique}

URL : http://journals.openedition.org/studifrancesi/8988

DOI : ERREUR PDO dans /localdata/www-bin/Core/Core/Db/Db.class.php L.34 : SQLSTATE[HYO00]

[2006] MySQL server has gone away

ISSN : 2427-5856

\section{Éditeur}

Rosenberg \& Sellier

Édition imprimée

Date de publication : 1 octobre 2008

Pagination : 480

ISSN : 0039-2944

\section{Référence électronique}

Lise Sabourin, «Théophile Gautier, L'Hirondelle et le corbeau, écrits sur Gérard de Nerval », Studi Francesi [En ligne], 155 (LII | II) | 2008, mis en ligne le 30 novembre 2015, consulté le 08 janvier 2021. URL : http://journals.openedition.org/studifrancesi/8988; DOI : https://doi.org/ERREUR PDO dans / localdata/www-bin/Core/Core/Db/Db.class.php L.34 : SQLSTATE[HY000] [2006] MySQL server has gone away

Ce document a été généré automatiquement le 8 janvier 2021.

\section{(c)}

Studi Francesi è distribuita con Licenza Creative Commons Attribuzione - Non commerciale - Non opere derivate 4.0 Internazionale. 


\title{
Théophile Gautier, L'Hirondelle et le corbeau, écrits sur Gérard de Nerval
}

\author{
Lise Sabourin
}

\section{RÉFÉRENCE}

THÉOPHILE GAUTIER, L'Hirondelle et le corbeau, écrits sur Gérard de Nerval, introduction et notes de Michel BRIX et Hisashi MIzUnO, Bassac, Editions Plein Chant, 2007 («L'Atelier du XIX ${ }^{\mathrm{e}}$ siècle»), pp. 221, ill.

1 Ce volume, dû aux deux grands spécialistes nervaliens que sont Michel Brix et Hisashi Mizuno, nous offre la première réunion des articles consacrés par Gautier à Nerval, son ami de collège dont il n'a cessé de souligner le talent, avant comme après sa triste fin, dans une intimité fidèle que même la maladie de Gérard ou le léger nuage de son portrait peu amène dans La Bohème galante ne sont pas parvenus à entamer. Cet ensemble, enrichi de trente-deux illustrations (portraits divers, lithographies et gravures sur ses interprètes dramatiques ou les lieux fréquentés), outre des vignettes d'Henri Monnier, Bertall, Gavarni, Eugène Lamy, présente ainsi ses commentaires sur Piquillo («La Presse», 6 novembre 1837), L’Alchimiste («La Presse», 15 avril 1839), Léo Burckart («La Presse», 22 avril 1839), Les Monténégrins («La Presse», 2 avril 1849), Une Nuit blanche («La Presse», 18 février 1850), Le Chariot d'enfant («La Presse», 22 avril et 21 mai 1850), L’Imagier de Harlem («La Presse», 30 décembre 1851), Les Illuminés («La Presse», 24 mai 1852), Le Voyage en Orient, Les Illuminés et Les Filles du feu («Le Moniteur universel», 25 février 1854), son article nécrologique («La Presse», 30 janvier 1855), sur la traduction de Misanthropie et repentir («Le Moniteur universel», 6 août 1855), la rue de la Vieille-Lanterne («L'Artiste», 9 août 1857), Le Voyage en Orient («Revue nationale et étrangère», 15 décembre 1860), la préface aux Oeuvres complètes (Michel Lévy, 1868, t. I), enfin, outre des articles sur L'Imagier de Harlem («Journal officiel», 19 avril 1869) et Léo Burckart («Gazette de Paris», 9 février 1872), les deux chapitres de l'Histoire du romantisme qui lui sont consacrés («Le Bien public», 21 avril et $1^{\text {er }}$ mai 1872). 
2 L'introduction des éditeurs (pp. 7-25) rappelle l'itinéraire serré des deux écrivains: son introducteur au Cénacle, hôte de l'impasse du Doyenné, Gérard collabore par intermittences (au rythme des voyages de Gautier, destinataire occasionnel du Voyage en Orient manuscrit) au feuilleton dramatique que rédige le plus souvent Théophile pour «La Presse». Et le dialogue se poursuit dans leurs œuvres: Deux Acteurs pour un rôle reprend le cadre des Amours de Vienne, tandis qu'Aurélia répond au Chevalier double. C'est donc tout naturellement qu'après son article nécrologique accablé, Gautier se voit confier par les frères Lévy la préface de l'édition de 1868 des Euvres de Nerval, dont useront Proust et Breton pour la postérité littéraire.

3 Gautier parle peu de Nerval en poète, selon une pensée commune en son temps, mais privilégie le dramaturge, domaine dans lequel il a beaucoup à nous apprendre, notamment sur les pièces perdues, comme Une Nuit blanche, ou modifiées à l'impression, telle Le Chariot d'enfant. Si Gautier reste discret sur la biographie de Nerval, dont il est pourtant mieux informé que d'autres, c'est qu'il préfère le voir en «fils de ses œuvres» (p.18) et donner à mieux cerner «l'hirondelle apode» qui s'est trouvée finalement brisée par «le corbeau» macabre dans sa quête d'équilibre «entre le rêve et le concret, l'idéal et la matière, la nuit et le jour, ou encore - lorsqu'il voyage entre la géographie magique et la couleur locale» (p. 24).

4 Outre l'analyse gautiériste $\mathrm{du}$ «microcosme» nervalien, qui fait preuve de son habituelle finesse dans la qualité des appréciations, ces articles permettent également de mieux appréhender la résistance à la poésie oraculaire et pindarique du premier romantisme qu'effectue le milieu fantaisiste des années 1835-1836, en s'intéressant aux formes d'art marginales (comme la chanson populaire), en s'opposant aux intentions «utilitaires» de l'art, en exaltant la sensation individuelle et la destinée «excentrique» du voyageur, qu'il soit simple flâneur ou vagabond nocturne, en recherchant le petit, le banal et le quotidien, jugés plus tard «réalistes» (p. 22). 